International Journal of Artificial Intelligence \& Applications (IJAIA), Vol.3, No.1, January 2012

\title{
ARTIFICIAL NEURAL NETWORK CONTROLLER FOR PERFORMANCE OPTIMIZATION OF SINGLE PHASE INVERTER
}

\author{
Shubhangi S. Ambekar ${ }^{1}$ and Madhuri A. Chaudhari ${ }^{2}$ \\ ${ }^{1}$ Department of Electrical Engg., K.D.K. College of Engg.,Nagpur, M.S., India \\ ambekar_ss@rediffmail.com \\ ${ }^{2}$ Department of Electrical Engg., Visvesvaraya National Institute of Technology, Nagpur, \\ M.S., India \\ macavc@yahoo.com
}

\begin{abstract}
Thyristorised Power control provides high efficiency. However, generated harmonics cause a nuisance in power system operation. The work presented here, deals with reduction of harmonics $\left(3^{\text {rd }}-11^{\text {th }}\right)$ by using Multiple Pulse Modulation technique. Traditional numerical methods do not yield accurate pulse-positions as non-linearity is involved in computation. In this paper, a continuous Hopfiled Neural Network is designed for Harmonic minimization in a $1 \Phi$ inverter output voltage. Results show considerable improvement in voltage spectrum if trigger pulses are generated at the ANN positions as harmonic contents are reduced with significant improvement in fundamental voltage resulting in reduction in device ratings. The ANN controlled voltage is used to drive a $1 \Phi$ Induction motor in MATLAB simulation and is compared with SPWM controlled VSI driving the same motor load. The quantitative analysis is given in tabular form. This shows feasibility of design of a controller for optimized performance of a single phase VSI.
\end{abstract}

\section{KEYWORDS}

Neural Network controller, Harmonic minimization, Performance optimization, Inverter, Motor control

\section{INTRODUCTION}

Thyristorised Power Control is widely used in the industry due to numerous advantages like high efficiency, compact size, long life, reduced maintenance, flexibility in operation, faster dynamic response, lower acoustic noise etc. However, the major disadvantage of thyristorised power control is that it invariably generates harmonics. They get injected in the power system networks and adversely affect the performance of loads connected to them [1, 2]. It, therefore, becomes necessary to reduce the harmonics generated by thyristorised appliances. Literature reports work done in the area of harmonic minimization [3,5,6]. A Method of Multiple Pulse Modulation with Selective Harmonic Elimination [4] can be effectively used to tackle the problem of harmonic elimination. However, it has limitations due to non-linearity involved in the voltage equations. The conventional methods of computations like Newton-Raphson cannot be successfully used as it requires the graphical approximation to be carried out as the initial stage. Thus, it is seen that the sinusoidal PWM technique is preferred over this method for controlling the inverters. To tackle the problem of non-linearity, intelligent techniques like Neural Networks and Evolutionary

DOI : 10.5121/ijaia.2012.3105 
International Journal of Artificial Intelligence \& Applications (IJAIA), Vol.3, No.1, January 2012

Programming are to be used [7-10]. Present work deals with the reduction of harmonics in the output voltage of a single phase inverter which forms a basic part in most of the thyristorised applications. Inverters are mainly used to control the ac drives [11]. The ANN controlled inverter output is used to control a $200 \mathrm{~W}$, single phase Induction motor in MATLAB simulation. The results are compared with Sinusoidal PWM controlled voltage driving the same motor load.

\subsection{Reduction Of Harmonics In The Inverter Output Voltage}

It is observed that the output voltage of a single phase inverter has much higher harmonic content which makes them unsuitable for industrial applications. A method of Multiple Pulse Modulation with Selective Elimination of Harmonics [4] is considered to tackle this problem of harmonic minimization. Fig. 1 shows the output voltage waveform for a single phase inverter.

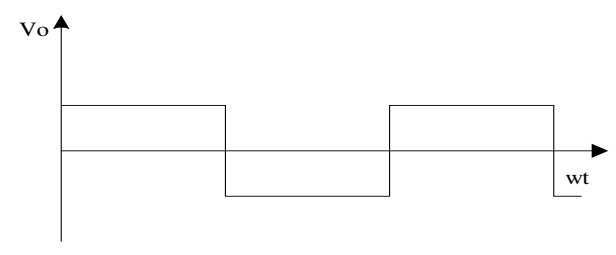

Figure 1. Voltage Waveform for a Single Phase Inverter.

\subsection{Selective Harmonic Elimination}

A process of Selective Harmonic Elimination (SHE) selects suitable pulse positions per quarter cycle to eliminate any $\mathrm{M}$ harmonics as shown in fig. 2 .

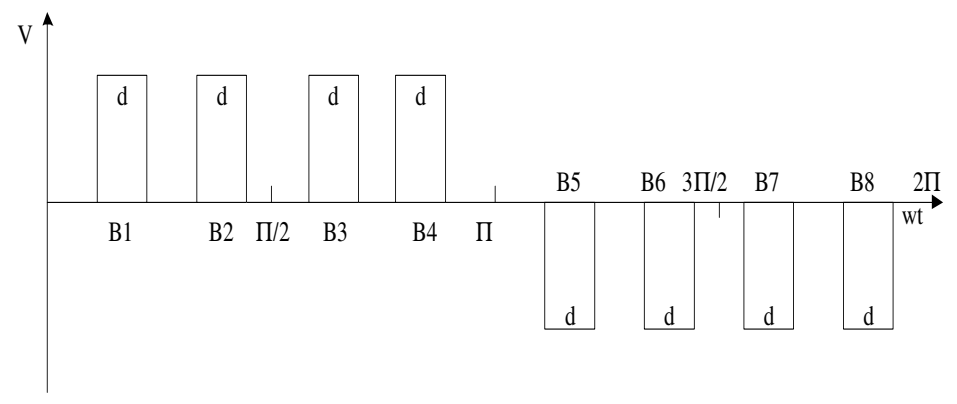

Figure 2. Pulse-positons for Multiple Pulse Modulation

The voltage variations are obtained by controlling the pulse-width symmetrically around these pulse-positions. Principally, all the pulse-widths are arranged to be equal. Quarter wave symmetry describes the above waveform as a set of non-linear transcendental equations as shown below:

$$
V o=\sum_{R=1}^{M} \frac{4 V}{\pi} \int_{E_{k=1}}^{E_{k+a}+a} \sin n w t d(w t)
$$

Where, $\mathrm{B}_{\mathrm{k}}=\mathrm{k}^{\text {th }}$ Pulse-position

$\mathrm{n}=$ Harmonic numbers to be eliminated, 
International Journal of Artificial Intelligence \& Applications (IJAIA), Vol.3, No.1, January 2012

$\mathrm{M}=$ Total number of harmonics to be eliminated

$\mathrm{V}_{\mathrm{o}}=$ Output voltage of inverter

$\mathrm{d}_{\mathrm{k}}=$ Pulse-width of the respective pulse

$$
V_{0}=\frac{8 V}{n L I} \sum_{k=1}^{M} \sin n d_{k} * \sin n B_{k}
$$

Thus, M harmonic components of voltage or current can be eliminated by equation (2) to zero, i.e.,

$$
\sum_{R=1}^{M} \sin n B_{k}=0
$$

This equation results in $\mathrm{M}$ non-linear algebraic simultaneous equations with $\mathrm{M}$ unknowns. If the voltage pulses shown in fig. 2 are of unequal widths as shown in fig. 3 , the voltage expressions take the following form:

$$
V_{o m m}=\Sigma \Sigma \sin n d_{k} * \sin n B_{k}
$$

Where, $\mathrm{V}_{\mathrm{onm}}=$ Magnitude of respective harmonic component,

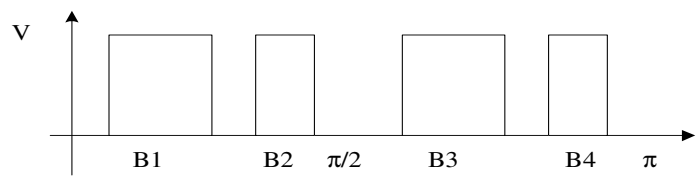

Figure 3. Voltage Pulses of Unequal width

Above expression produces a set of $\mathrm{M}$ transcendental equations with $2 \mathrm{M}$ unknowns. Now, the system of equations becomes unsolvable as far as conventional numerical techniques, like Newton-Raphson method, are considered. In order to eliminate complete lower order of harmonics, i.e., $3^{\text {rd }}, 5^{\text {th }}, 7^{\text {th }}, 9^{\text {th }} \& 11^{\text {th }}$, above set of equations gets converted into a set of nonlinear simultaneous equations with multiple unknowns.

\section{TECHNIQUES FOR OPTIMIZATION}

\subsection{Newton-Raphson Method}

For a set of non-linear equations, if the initial estimate for the solution vector is $\mathrm{x} 1, \mathrm{x} 2, \ldots \ldots .$. $\mathrm{xn}$ and $\Delta \mathrm{x} 1, \Delta \mathrm{x} 2, \ldots, \Delta \mathrm{xn}$ are the corrections required for $\mathrm{x} 1, \mathrm{x} 2, \mathrm{xn}$ respectively, the equations can be expanded by the Taylor's theorem to give the following matrix form :

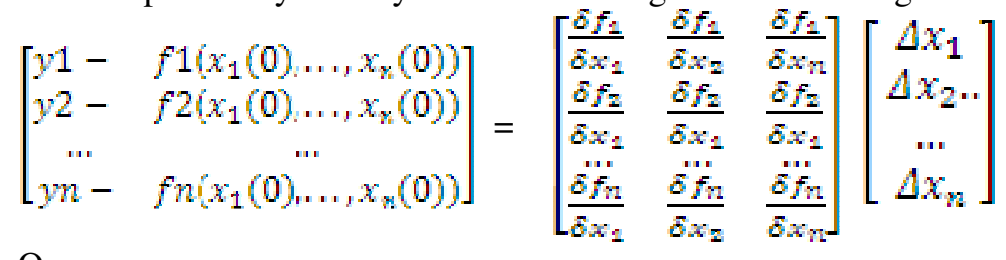

Or 
Where, $\mathrm{J}$ is the Jacobian for the functions $\mathrm{f} 1$ and $\mathrm{C}$ is the change vector $\Delta \mathrm{xi}$. The elements of the matrices D and $\mathrm{J}$ are evaluated by substituting the current values of xi's till the desired accuracy is reached. Thus, this is an optimisation problem wherein the amplitudes of the harmonic components are to be minimised and that of the fundamental component is to be maximised [7].

Newton-Raphson method suffers from a number of disadvantages for such kind of optimisation problems, e.g., it requires proper initial approximation for proper start, first derivate of the function should not be equal to zero, otherwise the process requires a restart etc., which forces the use of Artificial Neural Network.

\subsection{Artificial Neural Network (ANN)}

Artificial Neural Networks are based on the functioning of the nervous system in the living beings. These networks are similar to the biological neural networks. Fig. 4 shows the modelled neuron used for artificial neural network.

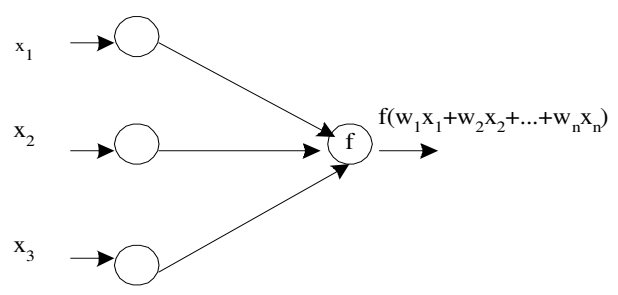

Figure 4. Artificially modeled Neuron

ANN is a parallel distributed processing system handling a group of interconnected neurons designed to perform some intelligent task $[9,10,11]$. A continuous Hopfield neural network with five nodes corresponding to five pulse-positions is designed for the optimization of set of equations given in (5) with an aim to eliminate lower order harmonics. This network attempts to minimize the energy function, which decreases monotonically with number of iterations. Five pulse-positions, b1, b2, b3, b4, b5 act as the nodes in a symmetrical fully connected network as shown in fig. 5. The above problem can be redefined as an optimization task to find suitable pulse-positions for simultaneous minimization of the complete lower order harmonic components, i.e., $3^{\text {rd }}, 5^{\text {th }}, 7^{\text {th }}, 9^{\text {th }}$ and $11^{\text {th }}$ order as given by expressions ( 7 ).

$\operatorname{Min}\left(F_{k}\right)=\sum_{k=1}^{M} \sin \pi B_{k} \quad \sin \pi \varepsilon_{k}$

Where, $F_{k}=$ Output to be optimised 
International Journal of Artificial Intelligence \& Applications (IJAIA), Vol.3, No.1, January 2012

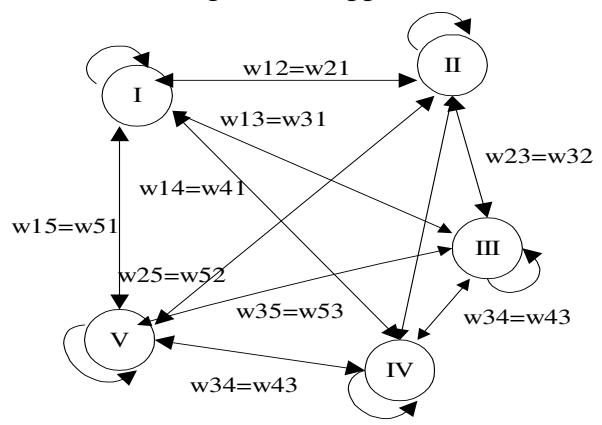

Figure 5. Hopfield Neural Network for Pulse-positions

The network equations are represented by (8) subject to given constraints.

$B p_{k(t+1)}=n * \operatorname{sgn}\left(\sum_{j=1}^{M} W_{k j} B p_{j(t)}+B_{k}\right)$

Where, $B p_{k(t)}$ represents an array of pattern $p$ at time $t$,

$B p_{j(t)}=$ activation of the $\mathrm{j}^{\text {th }}$ neuron at time $\mathrm{t}$,

$B_{k}=$ Self - bias.

$\mathrm{W}_{x y}=$ connection weight between neuron $\mathrm{x}$ and neuron $\mathrm{y}$,

$W_{x y}=W_{y x}$ for continuous Hopfield network for Energy Minimization function.

$n=$ learning rate of the network,

$\operatorname{sgn}=1 /(1-\exp (-B))$, Sigmoidal function.

For $0 \leq \mathrm{B}_{\mathrm{k}} \leq \Pi / 2$,

$-0.8 \leq W_{x y} \leq 0.8$

It is assumed that each node's output at each instant must belong to the closed interval $[0, \pi / 2]$, i.e., $0 \leq \mathrm{Bk} \leq \pi / 2$ for the $\mathrm{k}^{\text {th }}$ node. The node values are updated based on its instantaneous net weighted input. A sigmoidal function is selected for application to the sum of weighted net inputs due to its continuous, differentiable, rotationally symmetric and asymptotic nature. The node update rule is given by the expression (9).

$\frac{\delta E_{k(0)}}{\delta t}=0$ if $B_{k}=0$ and $\operatorname{sgn}\left(\Sigma W_{k j} B p_{j(t)}+B_{k}\right)<0$
$\frac{\delta E_{k(t)}}{\delta t}=0$, if $B_{k}=\pi / 2$ and $\operatorname{sgn}\left(\Sigma W_{k j} B p_{j(t)}+B_{k}\right)>\pi / 2$
$\frac{\delta E_{k(t)}}{\delta t}=\mathrm{n} * \operatorname{sgn}(\Sigma W k j B p, j(t)+B k) \quad$ otherwise 
International Journal of Artificial Intelligence \& Applications (IJAIA), Vol.3, No.1, January 2012

\subsection{Evolutionary Neural Network}

Artificial Neural Networks offer an attractive paradigm for the design and analysis of adaptive, intelligent systems for applications in artificial intelligence and cognitive modeling. However, the performance of ANNs for a particular problem is critically dependent on the choice of primitives (neurons or the processing elements), network architecture and the training algorithms. Most of the training algorithms used in ANNs search for the modifiable parameters, such as weights and the biases. In order that the ANN to succeed, the algorithm must be able to obtain the desired set of parameters in the given search space. The training algorithms like Gradient descent and the hill climbing techniques suffer from the drawback that they are susceptible to being stuck to the local minima. This presses for a new search technique with random or stochastic features. It must be able to escape from local optima and may possibly accept moves in the direction that are worse than the current state. An Evolution Programming concept possesses these characteristics and often obtains better solutions than the gradient descent or hill climbing methods.

An Evolution Program is developed for optimizing the connection weights for different nodes of the ANN. EP can take its own course in the given solution space to search for the best possible solutions. A graph in Fig. 6 shows a Random Search of Evolution Program around a Global Minima. Table 1 shows some connection weights used by the network.

Table 1: Optimum connection weights given by the Evolution Program (Bound on weights $[-0.8,0.8]$ )

\begin{tabular}{|c|c|c|c|c|c|c|c|}
\hline $\mathrm{W} 12$ & $\mathrm{~W} 23$ & $\mathrm{~W} 34$ & $\mathrm{~W} 45$ & $\mathrm{~W} 13$ & $\mathrm{~W} 14$ & $\mathrm{~W} 24$ & $\mathrm{~W} 15$ \\
\hline 0.251 & 0.182 & 0.124 & 0.128 & 0.000 & 0.006 & 0.209 & 0.119 \\
\hline-0.092 & 0.314 & 0.634 & 0.230 & 0.000 & 0.392 & 0.445 & 0.305 \\
\hline 0.7 & 0.705 & -0.8 & 0.65 & 0.000 & 0.75 & 0.8 & -0.6 \\
\hline 0.118 & -0.012 & 0.419 & 0.028 & 0.000 & 0.379 & 0.206 & 0.114 \\
\hline
\end{tabular}

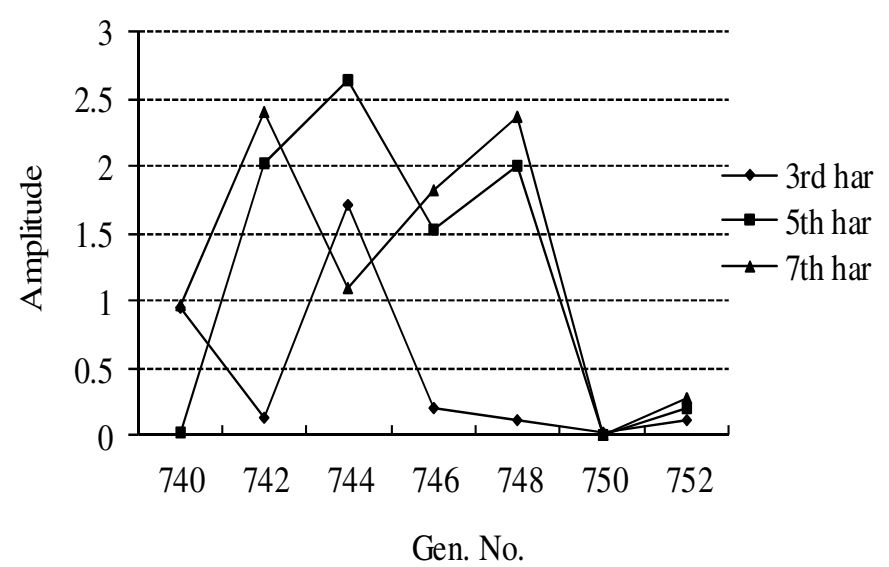

Figure 6. Fine tuning by Evolutionary Program around Global Minima 
International Journal of Artificial Intelligence \& Applications (IJAIA), Vol.3, No.1, January 2012

\section{RESULTS}

Feasible Pulse-positions for the elimination of complete lower order of harmonics, i.e., up to $11^{\text {th }}$ harmonic are obtained by Artificial Neural Network. A few sets given by the conventional technique of N-R method and ANN are listed in tables 2 and 3 below:

Table 2: Pulse-positions given by ANN(all angles in degrees)

\begin{tabular}{|l|l|l|l|}
\hline B1 & 19.6 & 20.6 & 29.3 \\
\hline B2 & 34.6 & 46.8 & 46.0 \\
\hline B3 & 48.7 & 53.6 & 63.9 \\
\hline B4 & 77.7 & 64.1 & 72.2 \\
\hline B5 & 87.5 & 82.6 & 86.5 \\
\hline
\end{tabular}

Table 3: Pulse-positions obtained using N-R method

\begin{tabular}{|c|c|c|c|c|c|}
\hline $\begin{array}{c}\text { Harmonics to be } \\
\text { eliminated }\end{array}$ & $3^{\text {rd }}$ & $5^{\text {th }}$ & $7^{\text {th }}$ & $9^{\text {th }}$ & $11^{\text {th }}$ \\
\hline $\begin{array}{c}\text { Pulse-positions } \\
\text { (angles in degrees) }\end{array}$ & 22.1 & 54.0 & 64.2 & 73.1 & 82.9 \\
\hline $\begin{array}{c}\text { Pulse-positions } \\
\text { (angles in degrees) }\end{array}$ & 23.6 & 55.7 & 64.8 & 71.6 & 86.7 \\
\hline
\end{tabular}

Fig.7 shows the variation of magnitude of fundamental voltage and harmonic components with respect to the half-pulse width (considering equal pulse-width at all positions as per the principles of Selective Harmonic Elimination Technique) at the positions given by ANN as calculated using equation (4).

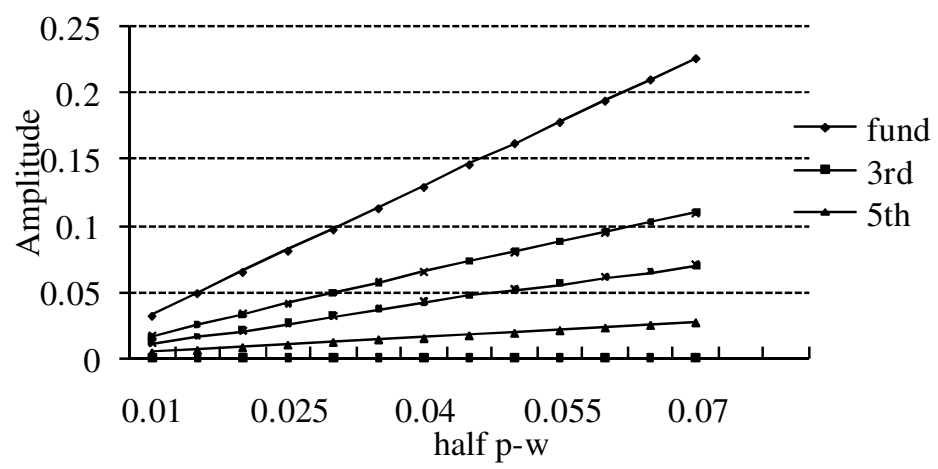

Fig. 7: Variation of Voltage w.r.t. Half - Pulse-width 
International Journal of Artificial Intelligence \& Applications (IJAIA), Vol.3, No.1, January 2012

Table 4 lists the pulse-widths, fundamental voltage, other harmonics and total harmonic distortion while Table 5 gives the comparison between two techniques. The graphs 8 and 9 show a considerable improvement in fundamental component and the THD.

Table 4: Pulse-widths, Fundamental Voltage, Other Harmonics \& THD (ANN \&EP Results)(angles in radians; other values in p.u.)

\begin{tabular}{|l|l|l|l|l|l|l|l|l|l|}
\hline $\mathrm{d} 1$ & $\mathrm{~d} 2$ & $\mathrm{~d} 3$ & $\mathrm{~d} 4$ & $\mathrm{~V}_{1}$ & $\mathrm{~V}_{3}$ & $\mathrm{~V}_{5}$ & $\mathrm{~V}_{7}$ & $\mathrm{~V}_{9}$ & $\mathrm{THD}$ \\
\hline $\begin{array}{l}0.028 \\
2\end{array}$ & 0.0283 & 0.0261 & 0.0235 & 0.0811 & $\begin{array}{l}0.00 \\
6\end{array}$ & 0.045 & $\begin{array}{l}0.00 \\
0\end{array}$ & $\begin{array}{l}0.01 \\
4\end{array}$ & $\begin{array}{l}0.58 \\
4\end{array}$ \\
\hline $\begin{array}{l}0.014 \\
8\end{array}$ & 0.0201 & 0.0186 & 0.0168 & 0.0576 & $\begin{array}{l}0.00 \\
5\end{array}$ & 0.032 & $\begin{array}{l}0.00 \\
0\end{array}$ & $\begin{array}{l}0.01 \\
0\end{array}$ & $\begin{array}{l}0.58 \\
7\end{array}$ \\
\hline $\begin{array}{l}0.014 \\
4\end{array}$ & 0.0196 & 0.0182 & 0.0164 & 0.0563 & $\begin{array}{l}0.00 \\
4\end{array}$ & 0.031 & $\begin{array}{l}0.00 \\
0\end{array}$ & $\begin{array}{l}0.01 \\
0\end{array}$ & $\begin{array}{l}0.05 \\
6\end{array}$ \\
\hline $\begin{array}{l}0.014 \\
8\end{array}$ & 0.0203 & 0.0186 & 0.0168 & 0.0576 & $\begin{array}{l}0.00 \\
5\end{array}$ & 0.032 & $\begin{array}{l}0.00 \\
0\end{array}$ & $\begin{array}{l}0.01 \\
0\end{array}$ & $\begin{array}{l}0.58 \\
7\end{array}$ \\
\hline $\begin{array}{l}0.011 \\
4\end{array}$ & 0.0155 & 0.0143 & 0.0129 & 0.0443 & $\begin{array}{l}0.00 \\
3\end{array}$ & 0.025 & $\begin{array}{l}0.00 \\
0\end{array}$ & $\begin{array}{l}0.00 \\
8\end{array}$ & $\begin{array}{l}0.58 \\
8\end{array}$ \\
\hline
\end{tabular}

Table 5: Comparison of Harmonic Voltages (p.u. Values)

\begin{tabular}{|c|c|c|c|c|c|c|}
\hline Technique & $\begin{array}{c}\text { Pulse- } \\
\text { width } \\
\text { (Degrees) }\end{array}$ & $3^{\text {rd }}$ & 5th & 7 th & 9 th & 11 th \\
\hline \multirow{3}{*}{$\begin{array}{c}\text { Newton- } \\
\text { Raphson }\end{array}$} & 1.5 & 0.0076 & 0.0037 & 0.0006 & 0.0054 & 0.0076 \\
\cline { 2 - 7 } & 3.0 & 0.0092 & 0.0074 & 0.0013 & 0.0107 & 0.0151 \\
\cline { 2 - 7 } & 4.5 & 0.1387 & 0.0111 & 0.0019 & 0.0159 & 0.0222 \\
\cline { 2 - 7 } & 6.0 & 0.0185 & 0.0147 & 0.0025 & 0.0208 & 0.0289 \\
\hline \multirow{3}{*}{$\begin{array}{l}\text { Hopfield } \\
\text { Network }\end{array}$} & 1.5 & 0.0000 & 0.0005 & 0.0012 & 0.0014 & 0.0022 \\
\cline { 2 - 7 } & 3.0 & 0.0001 & 0.0010 & 0.0023 & 0.0027 & 0.0043 \\
\cline { 2 - 7 } & 6.5 & 0.0001 & 0.0015 & 0.0035 & 0.0040 & 0.0063 \\
\hline
\end{tabular}

Figure 8. Total Harmonic Distortion for NR \& ANN Positions

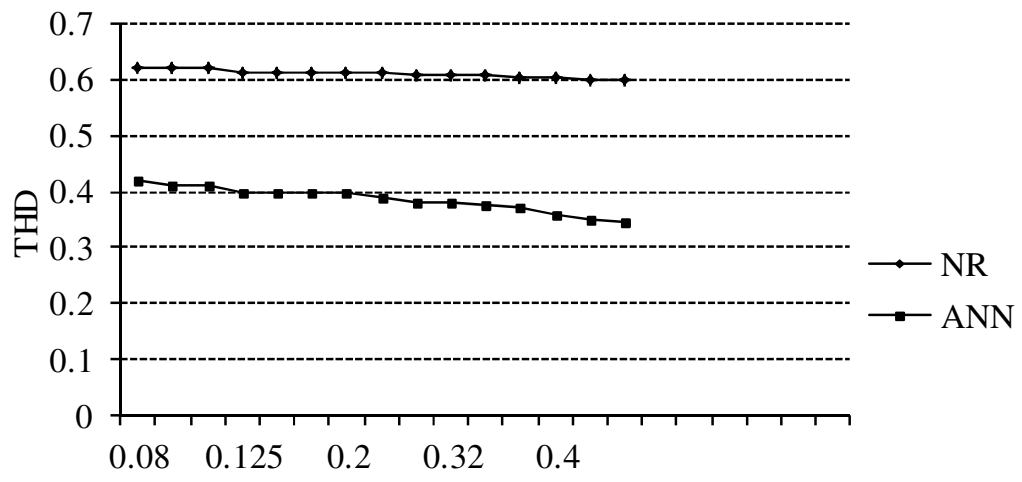

Half Pulse-width 


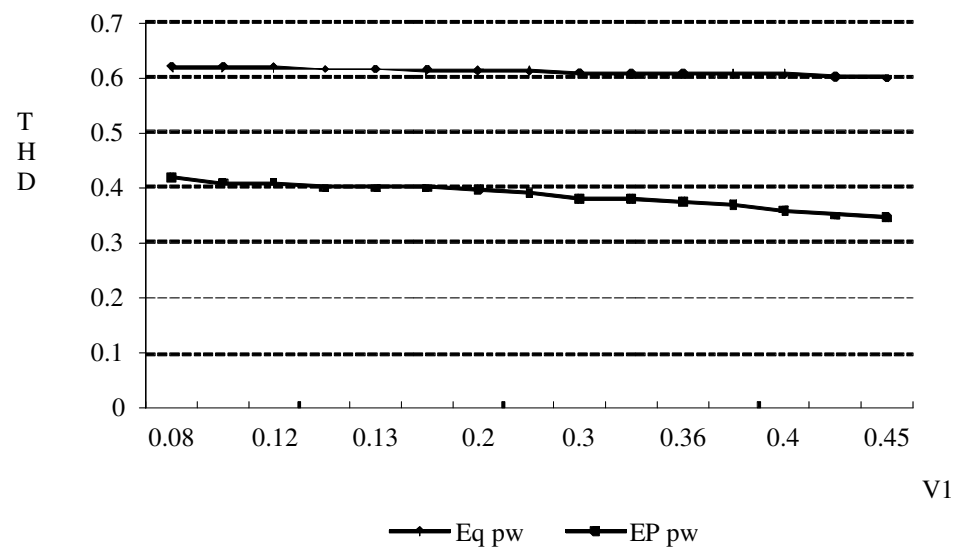

Figure 9. Variation of THD with Fundamental Components

It is observed from the above analysis that the traditional method like Newton-Raphson is not able to give satisfactory results due to the non-linearity involved in the problem definition. The Hopfield network produced the pulse-positions, which are reducing the lower order of harmonics to the extent of elimination, thus, improving the voltage spectrum considerably for a single phase inverter.

\section{MATLAB SIMULATION RESULTS}

The NR controlled and ANN controlled inverter is loaded with a $200 \mathrm{~W}, 230 \mathrm{~V}, 50 \mathrm{~Hz}$ single phase Induction Motor working at full load with a slip of 5\%. The Simulation is carried out in MATLAB - Simulink. Fig.10 shows the Matlab model of the system. Fig. 11 shows the output voltage of NR and ANN controlled simulated inverters. Table 6 gives the motor voltage and currents as produced by these two inverters. It can be clearly seen that the ANN controlled inverter gives higher output resulting in better performance of the Induction motor. Higher output voltage results in lowering the ratings of the devices with further reduction in cost.

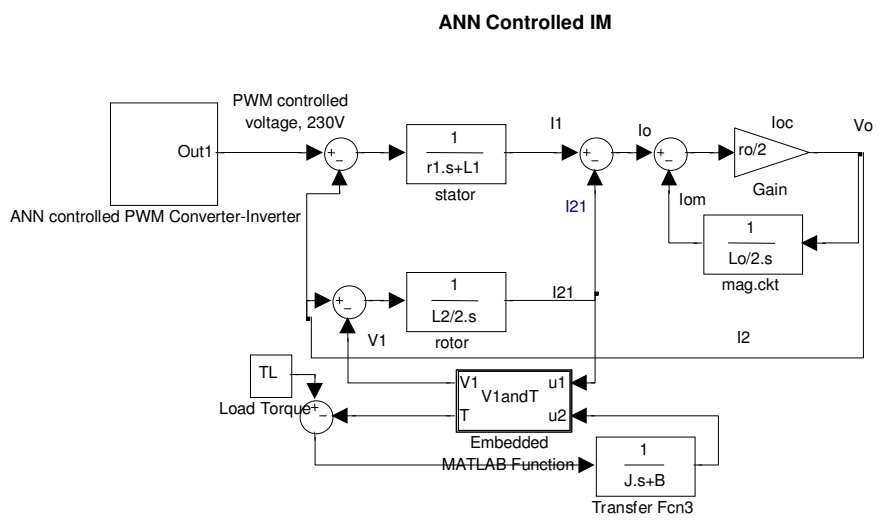

Figure 10. ANN controlled Inverter supplying single phase Induction Motor 
International Journal of Artificial Intelligence \& Applications (IJAIA), Vol.3, No.1, January 2012

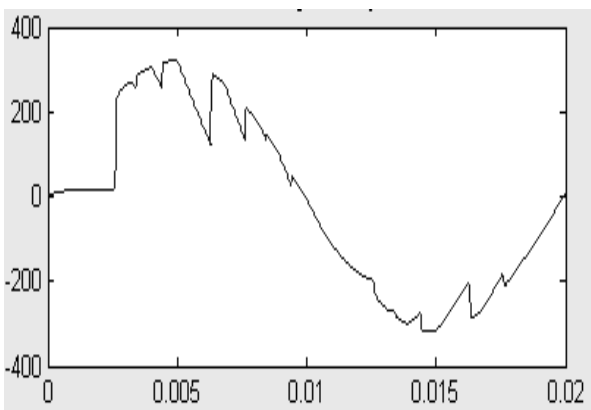

(a)

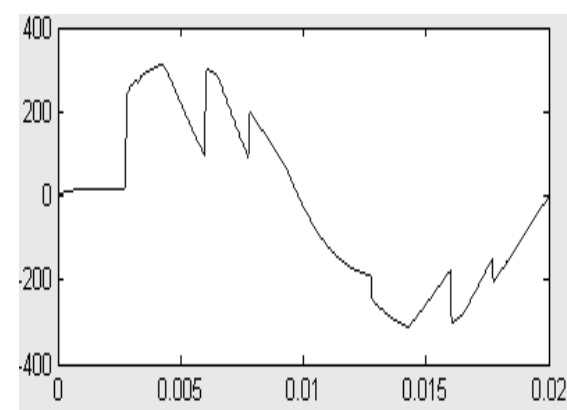

(b)

Figure 11. MATLAB Simulation Voltage waveforms for

(a)ANN -controlled Inverter

(b) NR - controlled Inverter

Fig. 12 shows the waveforms for Stator voltage, current and torque produced by the Induction motor driven by the ANN controlled inverter. These results are also compared with the torque produced by the Sinusoidal PWM controlled VSI driving the same motor load. Torque-slip characteristics for Induction motor controlled with sinusoidal PWM and controlled with ANN pulse-positions are shown in fig. 13. The simulation results show that the torque-slip curve is shifted upwards. A considerable improvement of about $15 \%$ is observed in torque, which is listed in table 7.

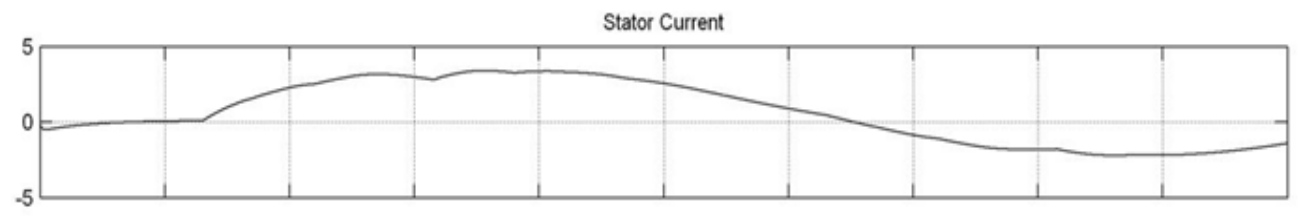

(a)

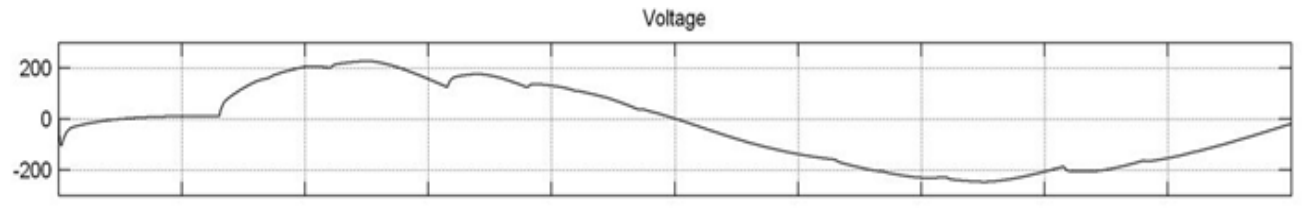

(b)

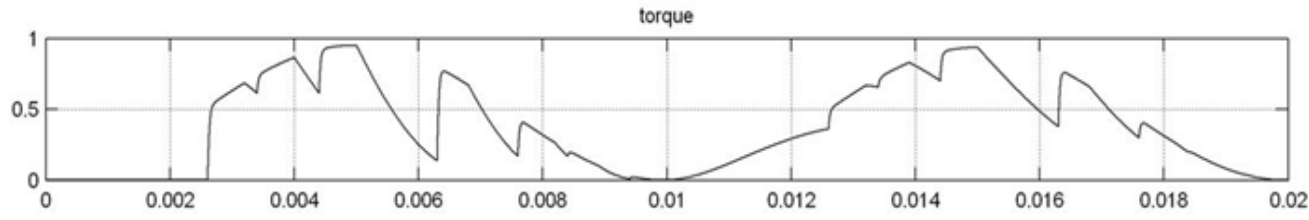

(c)

Figure 12. Waveforms for (a) Stator current (b) Stator Voltage (c) Torque 
International Journal of Artificial Intelligence \& Applications (IJAIA), Vol.3, No.1, January 2012

Table 6: Measured values in MATLAB Simulation for Induction Motor, slip $=5 \%$

\begin{tabular}{|l|c|c|c|}
\hline \multicolumn{1}{|c|}{ Technique } & $\begin{array}{c}\text { Stator Voltage } \\
\text { (peak values) }\end{array}$ & Stator Current (peak) & Torque Generated \\
\hline $\begin{array}{l}\text { N-R pulse controlled } \\
\text { inverter }\end{array}$ & $260.7 \mathrm{~V}$ & $2.69 \mathrm{~A}$ & 0.0135 \\
\hline ANN controlled inverter & $279.2 \mathrm{~V}$ & $2.99 \mathrm{~A}$ & 0.014 \\
\hline
\end{tabular}

Table 7: Comparison in Torque for IM controlled by SPWM VSI and ANN controlled VSI

\begin{tabular}{|c|c|c|c|c|}
\hline \multirow{2}{*}{ Slip } & \multicolumn{4}{|c|}{ Torque produced by Induction Motor } \\
\cline { 2 - 5 } & $\begin{array}{l}\text { SPWM } \\
\text { controlled }\end{array}$ & $\begin{array}{l}\text { ANN } \\
\text { controlled }\end{array}$ & Change & $\begin{array}{c}\text { increase in } \\
\text { torque }\end{array}$ \\
\hline 0.01 & 0.0038 & 0.0044 & 0.0006 & 15.79 \\
\hline 0.02 & 0.0153 & 0.0177 & 0.0024 & 15.68 \\
\hline 0.03 & 0.0343 & 0.0396 & 0.0053 & 15.45 \\
\hline 0.04 & 0.0610 & 0.0704 & 0.0094 & 15.41 \\
\hline 0.05 & 0.0954 & 0.1101 & 0.0147 & 15.4 \\
\hline
\end{tabular}

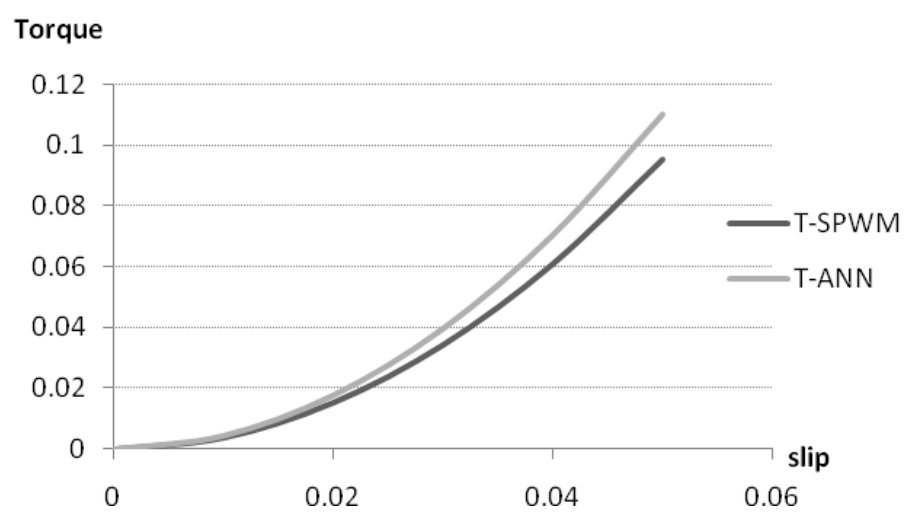

Figure 13. Torque-slip Characteristics for a Single Phase Induction motor

\section{CONCLUSION}

An Artificial Neural Network is developed for reducing the lower order of harmonics, i.e., $3^{\text {rd }}$, $5^{\text {th }}, 7^{\text {th }}, 9^{\text {th }}$ and $11^{\text {th }}$ in a single phase inverter circuit. It is observed that the results show a significant improvement in the voltage spectrum of the inverter. The harmonics are reduced to the extent of elimination with simultaneous increase in fundamental voltage component. Increase in output voltage results in reduction in ratings of the devices consequently reducing the cost. The torque-slip characteristics of a single phase Induction motor driven by the ANN controlled inverter also show a significant improvement of about $15 \%$ in torque developed as compared to the normally used sinusoidal PWM control for the Induction motor. Thus, the controller gives enhancement in the performance of a single phase inverter. 
International Journal of Artificial Intelligence \& Applications (IJAIA), Vol.3, No.1, January 2012

\section{REFERENCES}

1. D. Jang, G. Choe, " Asymmetrical PWM method for ac chopper with improved input power factor", IEEE PESC Conf. Rec. , 1991, pp 838 - 845.

2. R. L. Kirlin, Sam Kwok, S. Legowski, A. M. Trzynadlowski, " Power Spectra of a PWM Inverter with Randomized Pulse Position", IEEE Trans. on Power Electronics, Vol. 9, No.5, Sept. 1994, pp 463 472.

3. H. R Karshenas, H. A. Kajori, S.B. Dewan, " Generalized Techniques of Selective Harmonic Elimination and Current Control in Current Source Inverters/ Converters", IEEE Trans. on Power Electronics, vol.10, No. 5, Sept. 1995, pp 567-573.

4. K. A. Krishnamoorthy, G. K. Dubey, G. N. Revankar, "Converter Control with Selective Reduction of Harmonics", Proc. IEE, vol. 125, No. 2, 1978, pp 141-145.

5. S. R. Bowes, P.R. Clark, " Regular Sampled Harmonic Elimination PWM Control of Inverter Drives", IEEE Trans. on Power Electronics, Vol. 10, No. 5, Sept. 1995, pp 521-531.

6. Maxfred Grotzbach, Reiner Redmann, "Analytical Predetermination of Complex Line-Current Harmonics in Controlled AC / DC Converters", IEEE Trans. on Industrial Applications, Vol. 33, No. 3, May-June 1997, pp 601-611.

7. S. S. Ambekar, A. G. Keskar, "A Neuro-Evolutionary Approach to Selective Harmonic Elimination for a Single Phase Converter / Inverter", International Conference on Evolutionary Computing, Computer, Communication, Control \& Power, Chennai, Jan. 2000.

8. A Text Book on "Elements of Artificial Neural Networks", K. Mehrotra, C. K. Mohan, S. Ranka, Penram International Publishing, India.

9. Joy Mazumdar, R.G. Harley, F.C. Lambart, G.K. Venayagamoorthy, "Neural Network based Method for Predicting Non-linear Load Harmonics", IEEE Trans. On Power Electronics, vol.22, No. 3, May 2007, pp 1036-1045.

10. S. Joseph Jawhar, N.S. Marinuthu, "An Intelligent Controller for a non-linear Power Electronic Boost Converter", International Journal of Soft Computing 3 (1) : 69-73, 2008.

11. John W. Finch, Damian Giaouris, "Controlled AC Electric Drives", IEEE Trans. On Industrial Electronics, vol. 55, No. 2, Feb. 2008, pp 481-491.

\section{Authors}

1. Shubhangi S. Ambekar was born on $25^{\text {th }}$ April 1968. She received B.E (Electronics \& Power Engg.) degree from Visvesvaraya Regional College of Engineering, Nagpur and M.Tech. (By Research) from Visvesvaraya National Institute of Technology, Nagpur and is presently working as Associate Professor, Department of electrical engineering at K.D.K college of engineering, Nagpur, Maharashtra State, India. Her research interests are in the area of Power Electronics and ac drives. She is a member of Institution of Engineers (India) and Indian Society for Technical Education.

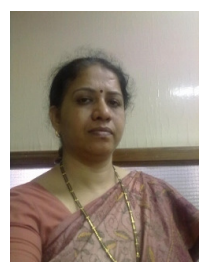

2. Madhuri A. Chaudhari was born in Maharashtra, India, on January 28, 1968. She received the B.E. degree from Amaravati university, Amaravati, India, M.Tech. degree from Visvesvaraya Regional College of Engineering, Nagpur University, Nagpur, India, and the Ph.D. degree from Visvesvaraya National Institute of Technology, Nagpur, all in electrical engineering. She is currently a Ass0ciate Professor with the Department of Electrical Engineering, VNIT, Nagpur. Her research interests are in the areas of power electronics, FACTS, and ac-dc drives. Dr. Chaudhari is a member of the IEEE, Institution of Engineers (India) and the Indian Society for Technical Education.

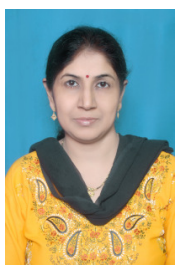

